\title{
PRESENCIA DE LA ESPAÑA DEL SIGLO XX
}

\author{
David Jorge \\ El Colegio de México
}

\section{INTRODUCCIÓN}

T a presente contribución busca ofrecer un balance cuantitatiـvo y cualitativo de la -en términos comparativos con otros países- muy sustanciosa presencia de España y de lo español en el siglo xx durante las siete décadas de trayectoria de la revista Historia Mexicana; es decir, una trayectoria iniciada en el ecuador mismo de la centuria que abordan estas líneas.

Omitiendo los trabajos que, aun estando lo español presente y explicitado en ellos, tengan como marco cronológico un periodo anterior al de la consolidación de España (así como de México), resulta notable el predominio del siglo XIx (la revista no ha publicado por el momento trabajo alguno relativo a las dos primeras décadas del presente siglo, al margen de alguna reseña con referencias al respecto).

\section{BALANCE CRONOLÓGICO Y TEMÁTICO E INTERPRETACIÓN DE LOS FOCOS DE ATENCIÓN ACADÉMICA}

En una aproximación mediante el buscador de la revista (excluyendo reseñas y salvando ciertas deficiencias, en cuanto a 
referencias duplicadas, ensayos de diferente naturaleza en cuanto a extensión u objeto de estudio, o vinculación no relevante en términos mínimos con lo español), los trabajos relativos al siglo XIX son dominantes. Entre los artículos referenciados en torno a la época contemporánea, el porcentaje de trabajos dedicados al siglo xIx dobla al correspondiente al siglo xx. Casi una cuarta parte de los trabajos cabalga entre ambos periodos, un porcentaje comprensible dado que el salto de siglo tanto en España como en México estuvo marcado por dos continuidades como lo fueron el régimen de la Restauración, por un lado, y el porfiriato, por el otro. Además, tanto la relación bilateral como la presencia española en México durante tal periodo ha concentrado una significativa atención académica, particularmente en el ámbito de las universidades mexicanas.

La bisagra intersecular concentra pues, en términos cronológicos, la mayor parte de las contribuciones relativas al siglo xx español. Le siguen, como segundo gran bloque concentrador de trabajos, las décadas de 1930 y 1940, con motivo del gran punto de encuentro histórico entre ambos países en la época contemporánea, como fue la Guerra de España con el consecuente exilio republicano en México, derivado del activo papel del cardenismo en ambos episodios.

Los temas estrella son tres: la historia de las relaciones bilaterales entre México y España en términos político-diplomáticos, el nacionalismo-intrínseco al bilateralismo anterior-y el exilio republicano español en México. Si bien en menor medida que las temáticas anteriores, ámbitos como la historiografía, la historia económica y la historia cultural tienen también una visibilidad importante.

\section{LA ESPAÑA DE LA RESTAURACIÓN Y LOS GACHUPINES, ENTRE EL PORFIRIATO Y LA REVOLUCIÓN}

No cabe duda de que, tras el considerable paralelismo histórico que se puede trazar entre el porfiriato y la España de la 
Restauración entre finales del siglo xix e inicios del xx, la revolución mexicana iniciada en 1910 marcó un punto de inflexión en todos los órdenes. La relación bilateral México-España, así como la situación de los españoles residentes en México, iban a cambiar radicalmente, toda vez que el marco ideológico bajo el cual se escudaron las diferentes familias revolucionarias pasaba por un nacionalismo a ultranza, de reivindicación indigenista, en el cual poca cabida se le otorgaba al componente peninsular de la mexicanidad. El nacionalismo revolucionario marcó de forma indeleble la evolución histórica de las mencionadas relaciones y, como no puede ser de otra manera, así quedó reflejado en los trabajos plasmados en las páginas de Historia Mexicana.

Dado el número de trabajos relativos al medio siglo comprendido entre las décadas de 1870 y 1920, resulta inviable comentarlas aquí de forma individualizada. El tema estrella del periodo, como es lógico, es el del nacionalismo. En tal sentido se pueden encontrar artículos que introducen muy bien la problemática por parte de un referente ineludible en la materia como Tomás Pérez Vejo, autor de "La conspiración gachupina en El hijo del Abuizote", así como "Reconquistar América para regenerar España. Nacionalismo español y Centenario de las independencias en 1910-1911", de Javier Moreno Luzón y, en un espectro más amplio en cuanto al periodo y más específico en el ámbito estudiado, “ ¿Negar o reescribir la Hispanidad? Los nacionalismos subestatales ibéricos y América Latina, 1898-1936”, de Xosé Manoel Núñez Seixas. Por último, siguiendo la estela del nacionalismo y su repercusión en la bilateralidad México-España, encontramos para periodos posteriores trabajos como "La colección de Etnografía e Historia de América y el embajador Roberto Levillier en México, 19341939”, de Alexandra Pita González, o “¿Nosotros, ustedes o ellos?: lo español en la memoria nacionalista de la arquitectura mexicana", de Johanna Lozoya.

El fervor nacionalista afectó naturalmente a cuestiones migratorias y al ámbito de las relaciones diplomáticas entre ambos 
países (segundo tema predominante en cuanto a foco académico). En el primer campo se encuentran trabajos como "La repatriación gratuita de inmigrantes españoles durante la Revolución Mexicana, 1910-1920”, de Alicia Gil Lázaro. En cuanto a diplomacia bilateral, la cobertura es idónea, toda vez que se pueden hilar en sintonía cronológica -para todo el periodo referido- tres artículos: "España y México: relaciones diplomáticas, negocios y finanzas en el Porfiriato", de Clara E. Lida; "México y España: de la representación diplomática oficial a los agentes confidenciales, 1910-1915", de Josefina MacGregor, y "La diplomacia española en la época de Carranza: iberoamericanismo e hispanoamericanismo, 1916-1920", de Marina Zuloaga Rada.

En el ámbito de la historia económica, destaca el estudio comparativo, por medio de dos ciudades emblemáticas en el desarrollo industrial de México y España, elaborado por Mario Cerutti y Jesús María Valdaliso: "Monterrey y Bilbao (1870-1914). Empresariado, industria y desarrollo regional en la periferia".

\section{CALLISMO, CARDENISMO Y AVILACAMACHISMO ANTE UNA ESPAÑA EN GUERRA Y EXILIO}

El periodo de entreguerras significó un parteaguas histórico en España, al tiempo que un periodo trascendental en la vida política del México posrevolucionario. Pero significó asimismo un momento esencial en la relación bilateral en todos los ámbitos: político, diplomático, cultural y social. La proclamación de la II República Española había motivado la elevación al rango de embajador del nivel de relaciones diplomáticas entre ambos países, con un periodo especialmente feliz en las mismas, el bienio 1931-1933 (con el embajador Julio Álvarez del Vayo en México). Tras una prosaica rebaja de dicha cercanía durante el bienio radical-cedista entre finales de 1933 e inicios de 1936, la victoria del Frente Popular en España auguraba unos nuevos tiempos, especialmente cordiales con el cardenismo. Sin 
embargo, el inicio de la guerra en España en julio de 1936 iba a alterar por completo la naturaleza de la relación. Desde un primer momento, México se erigió (por medio de diplomáticos como Narciso Bassols o Primo Villa Michel, que dignificaron la política exterior mexicana haciendo lo correcto tanto legal como moralmente) en el actor que mejor comprendió el carácter de la contienda, concibiéndola como una guerra internacional confinada a suelo español, aparte de la guerra civil en sí misma. Dicha vertiente internacional era la que situaba el conflicto en la dinámica de la crisis general de entreguerras, con las consecuencias jurídicas que un acto de agresión y una violación a la integridad territorial y a la independencia política de un Estado implicaban en términos del derecho internacional de la época. Un marco legal de aspiraciones supranacionales cuyo eje rector era el Pacto de la Sociedad de Naciones, organismo multilateral mediante el cual los delegados mexicanos expusieron tan firme como repetidamente su postura. El desdén por el marco de convivencia internacional acordado tras la primera guerra mundial tendría la consecuencia más funesta: allanar el camino hacia una segunda guerra mundial. Evitar tal escenario había sido el objetivo primordial de quienes configuraron el nuevo orden internacional de la primera posguerra mundial. Menos de dos décadas después -es decir, apenas un suspiro en términos históricos-, todo aquello se había desmoronado entre prejuicios, temores y nuevo abandono de un sentido de la colectividad más allá de las fronteras.

La tan activa e impecable como solitaria posición mexicana no sirvió para alterar la balanza de fuerzas internacionales a favor de la causa democrática española. Pero, sin embargo, sí sirvió para salvar incontables vidas y acoger solidariamente a más de 20000 exiliados republicanos en suelo mexicano. Entre las consecuencias de aquel éxodo, masivo y heterogéneo, estuvo la creación de La Casa de España en 1938 y su reestructuración como El Colegio de México a partir de 1940. Alfonso Reyes y Daniel 
Cosío Villegas fueron los principales artífices de dicha iniciativa (y el segundo, gran impulsor de esta revista en su concepción primigenia), que dio acogida a muchos representantes del mundo académico, intelectual y cultural español que, durante el primer tercio del siglo xx, representaron la hasta aquel entonces mejor generación de la historia de España en tales ámbitos. De alguna forma, sus aportaciones a la vida mexicana contribuyeron a paliar la deuda contraída por los demócratas y antifascistas españoles con la solidaria acogida mexicana en dramáticas circunstancias tanto a escala individual como colectiva.

Sobre el papel mexicano en la Sociedad de Naciones, que reflejó un continuum en materia de política exterior desde antes ya del inicio de la guerra en España (estreno con motivo de la agresión de la Italia fascista en Etiopía), ha trabajado en profundidad -desde una posición bastante más realista que idealista en cuanto al balance en las motivaciones de los dirigentes mexicanos- Fabián Herrera León. En esta revista publicó un trabajo, "México y la Sociedad de Naciones: Sobre su exclusión e ingreso (1919-1931)”, trabajo que refleja las primeras raíces de su línea de investigación, que se prolongaría en el tiempo hasta el periodo que nos ocupa.

No obstante la extraordinaria importancia de la relación bilateral en el periodo 1931-1945, no abundan los artículos directos en Historia Mexicana. Si para el sexenio cardenista llama especialmente la atención la ausencia de trabajos, para la relación de Calles (menos estudiado desde la academia que Cárdenas) y España solamente tenemos el trabajo de Lorenzo Meyer, en tanto que para la presidencia de Ávila Camacho (para su primera mitad, específicamente) contamos con el de Abdón Mateos.

En “Calles vs. Calles. El 'Jefe Máximo’ con la República, el exiliado con Franco. Contradicciones de la élite revolucionaria mexicana", Meyer analiza el giro de $180^{\circ}$ por parte del expresidente Calles hacia la República española. Si durante el Maximato se habían elevado las relaciones diplomáticas al rango de 
embajada y se vivió el mejor episodio entre ambos países en sus trayectorias históricas como estados independientes, el enfrentamiento abierto entre Calles y Cárdenas a partir de la llegada a la presidencia del segundo motivó un giro en la apropiación de la causa republicana por parte de la élite revolucionaria mexicana. A ello se sumaba el dejarse querer por parte de Calles respecto a la derecha y el conservadurismo nacionales, dada la polarización del país a partir de las decididas reformas sociales implementadas por el cardenismo. Todo ello llegó a su punto álgido con motivo de la elección presidencial de 1940, con la candidatura de Juan Andrew Almazán con serias posibilidades de llegar al poder. Al margen de ello, abonaba un elemento ideológico previo presente ya en Calles desde sus años en el poder: su marcado anticomunismo. Pese a que Calles llegó a acercarse al régimen franquista con el fin de dar un golpe contra el cardenismo, la política conciliadora de Manuel Ávila Camacho una vez asumida la presidencia apaciguó a Calles, repatriándolo y reinsertando su figura dentro del relato revolucionario. Como bien señala Meyer, la posición de Calles hacia España "no es más que una ilustración extrema de la ambigüedad y contradicción ideológica de la élite revolucionaria mexicana”. Y también una ilustración extrema, cabría añadir, del papel definitorio de las luchas personalistas y las circunstancias concretas, propias, nacionales e internacionales, a la hora de configurar y reconfigurar la evolución ideológica.

Mateos centra su trabajo, "Tiempos de guerra, tiempos de desesperanza. La política de Ávila Camacho hacia España y el exilio republicano en México, 1940-1943”, en la primera fase del exilio republicano en México, coincidente con la primera fase de la segunda guerra mundial, en la que México ingresaría a mediados de 1942. El artículo narra las dificultades, divisiones, reacomodos, discretas inserciones en el mundo político y sindical mexicano y derivas político-ideológicas de los exiliados republicanos en México durante el mencionado periodo. Se 
pone un especial énfasis en la JARE y en las restricciones migratorias implementadas por el gobierno de Ávila Camacho, menos decidido que el cardenista a la hora de concebir las libertades de los exiliados en suelo mexicano, y dentro de cuya Secretaría de Relaciones Exteriores (Ezequiel Padilla) se llegó a barajar la posibilidad de establecer relaciones diplomáticas con el régimen franquista.

En un amplio trabajo titulado "Mexicanos por naturalización en la primera mitad del siglo xx. Un acercamiento cuantitativo”, Pablo Yankelevich presta especial atención al caso de españoles naturalizados en el marco cronológico correspondiente al primer lustro del exilio republicano en México. Dado que el propio autor contribuye en este mismo número con una aportación relativa a la presencia del tema migratorio en las páginas de esta revista, huelga aquí hacer mayor énfasis específico en el tema.

Dos extensos trabajos, de diferente naturaleza, giran en torno al famoso yate Vita y su significación en el devenir y divisiones del exilio republicano. Carlos Sola Ayape, en "El exilio puesto a prueba: la polémica periodística entre Indalecio Prieto y Alfonso Junco en torno al oro del Vita", se basa esencialmente en fuentes hemerográficas para analizar y contextualizar la polémica periodística entre el escritor mexicano Alfonso Junco y el factótum del exilio republicano en México, el exministro socialista Indalecio Prieto (al frente de la JARE y enfrentado al otro gran sector del exilio republicano, liderado -en la distancia- por el presidente Negrín y organizado con los más exiguos recursos del SERE). La posición de Junco sería un elemento más en el lado de la reacción de la derecha mexicana ante la llegada de los supuestos “rojos” españoles, que en su sector mayoritario tenían bien poco de comunistas, pero cuya fuerte división abonó su debilidad desde los primeros días del exilio. La consecuencia de tal división no fue otra que una ayuda vital de cara a la consolidación del general Franco en el poder después de 1945, derrotados sus aliados nazis y fascistas. Aurelio Velázquez 
Hernández, por su parte, profundiza por medio de material de archivo inédito hasta entonces en "En torno del asunto del yate Vita. Los recursos de la Junta de Auxilio a los Republicanos Españoles". Analiza asimismo Velázquez el entorno de Prieto, identifica a actores no tan reconocibles de aquel primer exilio, presenta una visión novedosa de la JARE y sus actividades y, lo más relevante, desmitifica -por medio de un pormenorizado estudio cuantitativo- diversos mitos creados y asentados en la historiografía en torno al Vita.

Para finalizar, cabe señalar dos breves pero clarificadores trabajos: el artículo de José Miranda - publicado de forma póstuma, a finales de los años sesenta- acerca de "La Casa de España”, germen de El Colegio de México (una vez que la medida, provisional en su origen, se consolidó en el tiempo -particularmente en vistas a los posibles riesgos derivados del cambio presidencial de 1940- en forma de definitividad). En él se señalan los orígenes de una iniciativa de acogida académica de carácter extraordinario, fruto de la solidaridad del régimen cardenista hacia los perseguidos republicanos españoles, así como de la voluntad de aprovechar su talento en beneficio del progreso cultural de México.

Cabría añadir que se trató de una contribución que paliaba la deuda, imposible de saldar, contraída por la solidaria acogida mexicana y en la que, además de a través de la propia Casa de España/El Colegio de México, tendrían asimismo un papel importante refugiados de diferentes generaciones en diferentes instituciones académicas y educativas en México (Universidad Nacional Autónoma de México, Instituto Politécnico Nacional, Instituto Luis Vives, Colegio Madrid, etc., e incluso una iniciativa bastante posterior como el Centro de Investigación y Docencia Económicas, concebido por la economista Trinidad Martínez Tarragó).

Por otro lado, destaca el muy temprano trabajo de Clara E. Lida en torno a la producción sobre historia de España desde 
México, una vez llegado el contingente de exiliados republicanos y, entre ellos, numerosos académicos que se insertaron en las universidades y el panorama intelectual del mundo mexicano. Lida no sólo se limita a constatar dicha producción -escasa en número-, sino que valora la labor formativa y la influencia intelectual de dichos profesores españoles entre sus alumnos en las universidades mexicanas. El texto hace un balance de las aportaciones por parte de reconocidas figuras de la historiografía española, como el geógrafo Leonardo Martín Echeverría, Américo Castro, Antonio Ramos Oliveira, Rafael Altamira, Juan Marichal, José Moreno Villa, Rafael Segovia, Anselmo Carretero, Ceferino Palencia, Pedro Bosch Gimpera, Alberto Jiménez, Ramón Iglesia o Joaquín Xirau, entre otros, para culminar en los significativos trabajos de José Gaos en torno a su maestro José Ortega y Gasset.

\section{PRESENCIAS BIOGRÁFICAS}

En el artículo "De la banca privada a la gran banca. Antonio Basagoiti en México y España, 1880-1911”, Carlos Marichal Salinas presenta la figura de un exitoso banquero (originario de la franja cantábrica del norte de España, contingente migratorio mayoritario en el México de la época) en el marco de sendos procesos de transformación y expansión económica aceleradas y paralelas en México y España. Para ello se analizan los factores biográficos, sociales y políticos cuya concatenación permite comprender mejor el éxito de una categoría de migrantes españoles durante el porfiriato. El caso de Basagoiti, fundador del Banco Hispano Americano, es asimismo significativo como ejemplo para explicar los cambios fundamentales y la modernización de las prácticas que afrontó el mundo empresarial de la época, así como el tránsito profesional de comerciantes (categoría estrella de los gachupines en el México del siglo xix) a banqueros privados y directivos de la gran banca y la heterogénea 
naturaleza de sus funciones, entre las cuales no estuvo un rol determinante en la configuración de los lazos hispano-mexicanos e hispano-americanos en general.

Por su parte, Andrés Lira da cuenta en "El hombre Ramón y otros papeles" de las tribulaciones y perturbaciones del historiador y profesor exiliado español Ramón Iglesia. Lo hace a partir de dos expedientes, localizados uno en el Archivo Histórico de El Colegio de México y otro en el de la JARE, que revelan el calvario del personaje tras su arribo a Berkeley-California y que, tras conducirlo del hospital a un centro psiquiátrico, tuvo un trágico final, ya como profesor en Madison-Wisconsin, en forma de aparente suicidio a sus 42 años. El texto expone, por medio de su correspondencia con Alfonso Reyes y Daniel Cosío Villegas (pues nunca interrumpió su vinculación con El Colegio de México), a un historiador sobrepasado mentalmente por la carga de trabajo autoimpuesta y que malamente disimula su angustia. Lira, al igual que otros historiadores mexicanos como Álvaro Matute, profundizarían en el estudio de la figura de Iglesia, quien pese a su demasiado corto periplo contribuyó notablemente a la renovación de la historia de la historiografía en México.

\section{AUSENCIAS: TEMAS POR ABORDAR EN LAS RELACIONES MÉXICO-ESPAÑA EN EL SIGLO XX}

En cuanto a los temas especialmente relevantes dentro del siglo xx y que están ausentes de las páginas de Historia Mexicana, destacan fundamentalmente los cinco bloques siguientes:

1. La relación bilateral durante los años veinte y treinta (previos al inicio de la guerra en España, en el verano de 1936). Pese a la abundancia, tanto por medio de libros como de publicaciones en otras revistas académicas, de trabajos relativos al papel mexicano en torno a la contienda española, así como cierta presencia de la relación durante el 
primer bienio republicano (1931-1933), sigue dándose una ausencia general de trabajos relativos a la relación MéxicoEspaña durante los años veinte (mandatos presidenciales de Obregón y Calles en México, crisis del régimen de la Restauración y dictadura de Primo de Rivera en España) y durante el periodo 1933-1936 (bienio radical-cedista y frente popular en España, y final del Maximato e inicios del sexenio cardenista en México), previo al estallido de la guerra;

2. la vinculación y acción transnacional conjunta (MéxicoEspaña-México) de determinados actores del movimiento comunista internacional, desde los orígenes mismos de los partidos comunistas de ambos países -a inicios de los años veinte-, y la proyección de la Komintern en los mismos -durante el periodo de entreguerras y la segunda guerra mundial-;

3. la relación bilateral en términos comerciales y culturales -ya que las relaciones diplomáticas fueron inexistentes, dado que el régimen priista nunca reconoció al franquistadurante la larga dictadura en España;

4. las diversas relaciones mantenidas entre emisarios de los sucesivos gobiernos mexicanos y personalidades de la oposición antifranquista durante los años finales de la dictadura y los inicios del proceso de transición hacia la democracia en España;

5. en un terreno de relaciones bilaterales y estudio comparativo, los virajes hacia la "modernidad" (entendida con matices diferentes pero esencias comunes, como el abrazo al neoliberalismo victorioso en la dialéctica bipolar de la Guerra Fría) que tuvieron lugar en 1982 (con los cambios de gobierno en ambos países y los giros en materia de política económica y exterior) y 1986 (ingresos respectivos en el GATT y en la Unión Europea, concebidos ambos como inmersiones naturales en virtud del entorno geopolítico a 
un lado y otro del Atlántico) en los dos países, así como la “economización” de la relación bilateral, perdiendo fuelle en materia de diplomacia y política exterior -no en el ámbito cultural-.

Pero si hay un terreno especialmente virgen por explorar es el de los dos últimos puntos, que abarcan el último medio siglo. En tal sentido, la lucha en torno a la apertura de archivos es una batalla que los historiadores, y el mundo académico e intelectual en su conjunto, todavía tienen por delante. Mantener cerrados a cal y canto los archivos correspondientes no puede responder ya a ningún riesgo relativo a la seguridad nacional o la respetabilidad internacional. La salud democrática de ambos países se beneficiaría de la transparencia y las facilidades a la hora de reconstruir los hechos de un pasado ya lo suficientemente lejano como para comenzar a ser explorado bajo una perspectiva histórica.

\section{CONCLUSIONES}

Dada la naturaleza de Historia Mexicana, en la que lo mexicano debe estar presente en una medida significativa en cada contribución, la presencia de España en la revista resulta especialmente relevante. Y, en términos nacionales, únicamente comparable a la de una potencia vecina como Estados Unidos, cuyo papel ha sido decisivo y cuasi permanente en el desarrollo histórico del México contemporáneo.

Si bien para periodos anteriores a la época contemporánea lo español ha tenido una presencia inmensa en la publicación, dados los íntimos lazos compartidos a lo largo de tres siglos entre novohispanos y peninsulares, los vínculos entre México y España como Estados nacionales independientes han seguido gozando de una posición privilegiada en la atención de los historiadores de este país. También en la atención de los académicos españoles, si bien en menor grado (en buena medida debido a la 
intrínseca vinculación, ya sea más o menos justificada, con que se presenta el proceso de modernización español en el marco de la integración comunitaria europea). No obstante, en la historiografía española también se ha privilegiado la especificidad mexicana por encima de otros países latinoamericanos. El grado de atenciones mutuas no es sino el reflejo de una relación excepcional a escala mundial, sin parangón en términos intercontinentales, tanto por la duración y profundidad de los vínculos como por la diversa naturaleza -en extremo compleja y heterogéneade los mismos. 